\title{
TREATMENT OF HIV/AIDS IN THE MANAGED CARE SETTING
}

\author{
Leighton McDonald, $M B C h B, D O H$ \\ Mx Health Institute, Centurion, South Africa
}

HIV and AIDS is having, and will continue to have, a significant effect on the private health care industry in South Africa. A number of clinical, financial, legislative and ethical questions need to be addressed in deciding on an effective and sustainable response to the challenge posed by the epidemic.

The maturation of the epidemic from an HIV to an AIDS epidemic has resulted in increased health care costs for employers, medical schemes and individuals. This increased expenditure has not always resulted in a favourable outcome and there is an urgent need to address the funding of HIV/AIDS management in a rational way to ensure optimal utilization of scarce resources

\section{COSTS OF HIV/AIDS}

HIVIAIDS has a financial impact on all aspects of South Africa. The costs can be categorised as follows:

\section{MEDICAL COSTS}

These are widely quoted as they are often the most tangible evidence of the impact of the condition. Included are the costs of:

\section{Consultations \\ Investigations Diagnostic and monitoring \\ Medication Antiretroviral, prophylaxis and treatment of opportunistic infections \\ Hospitalisation Management of opportunistic infections}

\section{COUNSELLING}

The above are costs which can be directly attributable to HIVIAIDS; they are not exhaustive and do not include the indirect costs associated with increased utilisation of general health care services that may occur as a result of ill health.

\section{EMPLOYER COSTS}

The employer is exposed to costs in a range of areas, including:

\section{Absenteeism}

In the form of sick leave for infected employees, but also for employees who are caring for infected family and for those attending the increasing number of funerals.

\section{Loss of productivity}

Productivity will be affected not only by absenteeism but by the fact that ill employees and those who are concerned about ill family members are less likely to be fully productive and are more likely to have accidents in the workplace.

\section{Recruitment}

Costs of recruitment will increase as employees need to be replaced. Legislation excludes pre-employment HIV testing - in areas of high prevalence it is possible that a significant percentage of new recruits will themselves be HIV-infected.

\section{Training}

Additional training will be required, not only for new employees but in order to increase the range of skills held by employees in order to equip them to deal with a wider variety of occupations where necessary.

\section{Employee benefits}

The cost of maintaining employee benefits is set to rise dramatically as the health of the workforce deteriorates. Benefits affected to the greatest degree include pension, disability and health care cover. In the face of this scenario it is likely that employees will increasingly offer a finite package to employers and pass the responsibility for pension and health care cover on to the employees. While this will achieve the objective of capping the risk for the employer, it is unlikely to benefit the employee who will be tempted to utilise the full package for immediate material needs rather than pension and health care.

\section{SOCIAL AND COMMUNITY COSTS}

The consequences of a high burden of dead and dying patients will affect every aspect of the community, from the increased responsibility of caring for the ill and the overburdening of the extended family in absorbing children orphaned by the epidemic through to the relative chaos caused by the loss of a traditional social structure.

\section{ECONOMIC COSTS}

All of the aforementioned factors will ultimately place downward pressure on the economy, since HIV/AIDS has introduced additional costs to an economy ill-equipped to deal with this load. Investor confidence may be affected as 
the competitiveness of South African business is compromised. The numbers of unemployed persons may increase as a result of the demise of marginal businesses.

\section{EFFECT ON MEDICAL SCHEMES}

HIV/AIDS has increased costs for medical schemes, and as a result the cost of contributions for employers and individuals has risen. It must be noted that HIVIAIDS is only one of a number of factors that has caused an escalation in health care costs.

To understand the effect that HIVIAIDS has on the funding of health care it is useful to revisit the economic principle upon which the funding of medical schemes is based, namely cross-subsidisation. Traditionally a contribution has been made to a medical scheme, whether use was made of the benefits or not. In this way those who paid more than they used were subsidising those who used more than they paid - provided the total claimed from the scheme was lower than total contributions, the scheme was financially viable.

This can be explained by means of simple graphs (Figs 1 and 2).

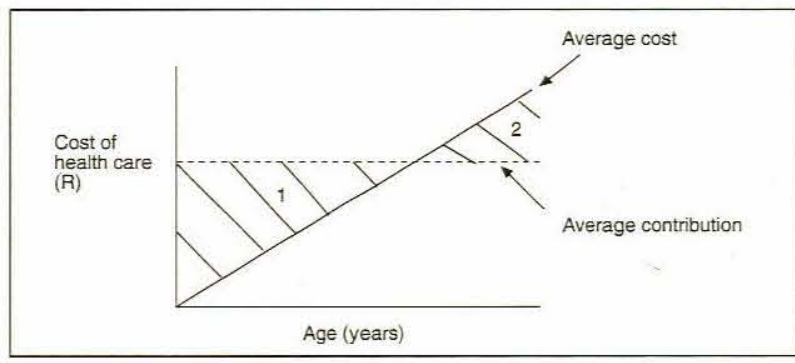

Fig. 1. Health care costs by age of member (before HIVIAIDS). 1 = money received (by means of the average contribution) and not paid out in health care claims; 2 = money required (over and above the average contribution) to pay health care claims.

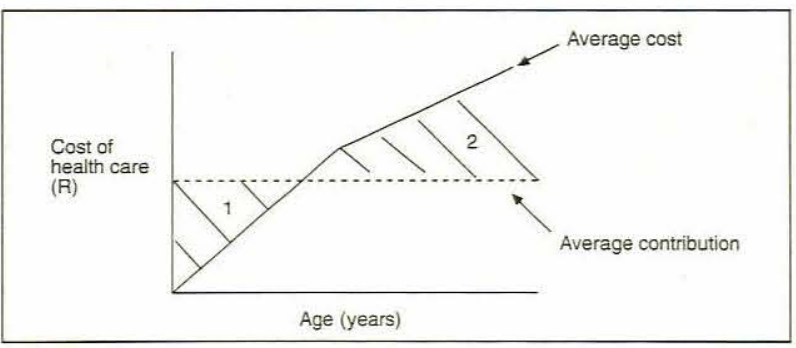

Fig. 2. Health care costs by age of member (with HIV/AIDS). 1 = money received (by means of the average contribution) and not paid out in health care claims; 2 = money required (over and above the average contribution) to pay health care claims.

Before the advent of HIV/AIDS the average health care costs of members were related to age, largely owing to an increase in the incidence of age-related conditions (heart disease, cancer, stroke, etc.) in the elderly. The costs of managing the conditions were met from contributions, since there was a young, healthy sector of the membership who were not experiencing high health care expenses, i.e. provided the monetary value represented by (1) was greater than that represented by (2), the scheme was financially viable.
With the advent of HIV/AIDS an additional cost burden has been introduced and, since this is an illness that hits hardest in the young, healthy population, the health care costs of these individuals have escalated and the portion of these contributions which previously subsidised the treatment of the elderly and the sick is no longer available for this purpose i.e. the monetary requirement represented by (2) is now in excess of the monetary surplus represented by (1).

The scenario outlined above has necessitated a review of the funding of HIV/AIDS management.

\section{PROVISION OF AN HIVIAIDS BENEFIT}

The promulgation of the Medical Schemes Act (Act 131 of 1998) outlined certain responsibilities for medical schemes with regard to HIVIAIDS management. These are stipulated in Section 29 (1) of the Act and refer to a set of prescribed minimum benefits (PMB) which any entity carrying out the business of a medical scheme is compelled to fund.

The PMB stipulates hospital inpatient care for a range of conditions including :

\section{Diagnosis HIV-associated disease}

Treatment Medical and surgical treatment of opportunistic infections and localised malignancies

The Act does not enforce the use of antiretroviral therapy for the management of HIV-infected medical scheme members, but an argument has been raised that the use of these drugs (and the funding thereof) would maintain the health status of the patient and prevent costs associated with advanced HIV disease.

Is the management of HIV/AIDS with antiretroviral therapy cost-effective in the South African private health care setting?

While it would appear to be common sense to provide optimal therapy initially to control the disease (as with other chronic conditions such as asthma and diabetes mellitus), HIV presents some unique problems.

\section{AFFORDABILITY OF MEDICATION}

Antiretroviral medication, despite the recent price cuts, is not inexpensive and the fact that at least two antiretroviral drugs are required in combination adds significant expenses to medical schemes.

Using a simple calculation for a scheme of 20000 lives and assuming an average antiretroviral medication cost of R2 500 per month, the annual cost for antiretroviral therapy is as follows:

$2 \%$ prevalence

400 patients $\times$ R2 $500 \times 12$ months $=R 12000000$

$5 \%$ prevalence

1000 patients $\times$ R2 $500 \times 12$ months $=$ R30 000000

$10 \%$ prevalence

2000 patients $\times$ R2 $500 \times 12$ months $=R 60000000$ 
The spend on antiretroviral medication is an additional cost for the scheme and will ultimately need to be covered by way of increased member contributions.

Costs will obviously be dependent on the scheme's HIV prevalence, the rate at which patients present for treatment and the protocols used for therapy. The scheme should assess the potential liability prior to deciding on a benefit.

\section{HOSPITALISATION CONTINUES}

The provision of antiretroviral therapy does not guarantee a large decrease in hospitalisation costs, for the following reasons:

- Treatment failure will occur in a percentage of cases, either due to viral resistance or to sub-optimal compliance.

- Patients presenting with advanced disease may require periodic hospitalisation despite antiretroviral therapy. Terminal care may be required in end-stage disease.

\section{PERCEIVED DISCRIMINATION}

The provision of an additional financial benefit for the management of HIV-infected members may be seen as unfairly discriminating against members of the scheme who have other health care requirements that are not funded by the scheme, e.g. an asthmatic patient whose chronic medication benefit is insufficient for full coverage of required chronic medication.

The provision of an additional benefit for HIV treatment also translates into higher member contributions for all members.

All these factors, along with other costs of managing HIV, need to be considered in the compilation of the annual medical scheme benefits (and budget).

\section{POSSIBLE SOLUTIONS}

There are a number of measures that can be taken by the scheme to optimise the benefits offered to HIV-positive members.

\section{SECURE ADDITIONAL FUNDING}

In closed, employer-based medical schemes 'top-up' funding should be secured from the employer - who stands to gain from the maintenance of the health status of employees.

Increasingly, employers are realising the benefits of providing a benefit for the management of HIV-positive employees and this represents an opportunity for cooperation between the employer and the medical scheme.

\section{DISCOUNTED MEDICATIONS}

The cost of antiretroviral medications has been falling, but there is further scope for medical schemes to negotiate favourable pricing with pharmaceutical companies. This is particularly valid for large medical schemes where volumebased discounts are feasible.

\section{INNOVATIVE TREATMENT PLANS}

Treatment guidelines need to be tailored for specific clinical and financial circumstances. Possibilities include:

\section{Delayed treatment}

While it is accepted that treatment should not be initiated above a CD4+ count of $350 \mathrm{cell} / \mathrm{s} / \mathrm{ml}$, there may be some value in lowering this value to 250 . Research is ongoing.

\section{Interrupted treatment}

This implies 'treatment holidays', e.g. two months on treatment followed by a month off, which effectively reduces the cost of treatment by one third.

\section{Stepped treatment regimens}

A narrow range of robust treatment should be utilised initially with access to more complex (and expensive) combinations restricted to specialist use.

\section{Curtailed treatment}

An end-point could be set beyond which a decision is made to curtail ARV and provide palliative care only.

Decisions on treatment should always be evidence-based to promote a favourable health outcome.

\section{DISEASE MANAGEMENT}

The complexity of the condition and its management make it essential that any medical scheme providing a benefit for HIV management ensures that a disease management programme is in place to support the patient and the treating practitioner.

Elements of a disease management programme include:

\section{Comprehensive patient assessment}

- Treatment guidelines/protocols

- Critical pathways (which investigations/interventions need to be carried out and at which time intervals)

- Patient education, support and counselling

- Health status monitoring

- Outcomes measurement (health status, quality of life, economic).

The treating practitioner should be assisted, where necessary, in the selection of the most appropriate medication and the patient should be empowered with information to manage the disease optimally (e.g. compliance, lifestyle changes, etc.).

\section{CONCLUSION}

The costs associated with HIV/AIDS and its complications represent a large threat to the financial viability of medical schemes. Ignoring the problem will exacerbate the threat and schemes need to strive to find solutions that are nondiscriminatory, ethical and sustainable. Ongoing measurement of financial, clinical and quality outcomes needs to be accurately carried out for purposes of policy review should this be necessary. 